doi: $10.2306 /$ scienceasia1513-1874.2013.39.186

\title{
Strength and microstructure development in Bangkok clay stabilized with calcium carbide residue and biomass ash
}

\author{
Songsuda Vichan ${ }^{\mathrm{a}, *}$, Runglawan $\operatorname{Rachan}^{\mathrm{a}}$, Suksun Horpibulsuk ${ }^{\mathrm{b}}$ \\ a Department of Civil Engineering, Mahanakorn University of Technology, Bangkok 10530 Thailand \\ b School of Civil Engineering, Suranaree University of Technology, Muang District, \\ Nakhon Ratchasima 30000 Thailand
}

*Corresponding author, e-mail: songsudavichan@gmail.com

Received 10 Oct 2012

Accepted 19 Feb 2013

\begin{abstract}
A mixture of biomass ash (BA) and calcium carbide residual (CCR) was used as a cementing agent for stabilization of soft Bangkok clay. The improvement in unconfined compressive strength of stabilized clay depends on the initial soil water content, binder content $(B)$, CCR:BA ratio, and curing time. The strength improvement can be classified into two zones: active and inert. In the active zone $(B=5-15 \%)$, the $\mathrm{Ca}(\mathrm{OH})_{2}$ content from the CCR is high and there are insufficient natural pozzolanic materials in the clay for the reaction. The input of $\mathrm{BA}$ increases the $\mathrm{SiO}_{2}$ content and induces the strength development. In the inert zone, (high binder content, $B>15 \%$ ), the free lime causes unsoundness and results in insignificant strength development. The hydration products from the pozzolanic reaction (ettringite and a calcium aluminate silicate hydrate compound, gismondine) are identified by microstructural analysis via X-ray diffraction (XRD), scanning electron microscope with energy dispersive X-ray spectroscopy (SEM with EDS), and X-ray fluorescence. SEM images show the compact morphology of the stabilized clay as the result of the increase in curing time and binder content. Over time, the cementitious products fill in the pore space, causing denser morphology and higher cementation bond strength between the clay clusters. The clay stabilized by XRD showed no reduction in the intensity of the reflection of the both quartz and kaolinite throughout the curing times. This implies that the amorphous silica from the glass of the BA is more reactive in dissolution in the CCR than the crystalline phase of quartz and kaolin in clay.
\end{abstract}

KEYWORDS: stabilization, pozzolanic reaction, C-A-S-H, unconfined compressive strength

\section{INTRODUCTION}

Fine-grained soils without stabilization are unsuitable for earth structures and pavement. The chemical stabilization is one of the extensively used techniques to improve the engineering properties of fine-grained soils. Portland cement is commonly used for this stabilization in Thailand. The resistance to compression and consequent strength development increase with increasing curing time. However, the high unit cost and energy intensive process of Portland cement is driving a search for alternative cementitious additives. For fine-grained soils, which contain high natural pozzolanic materials, $\mathrm{Ca}(\mathrm{OH})_{2}$ rich materials can be used to produce a moderately high strength geo-material ${ }^{1}$. The cementing property is identified as a pozzolanic reaction. The stabilization of clayey soils by $\mathrm{CaCl}_{2}$ and fly ash (FA) reduces the plastic index and improves the workability ${ }^{2}$. The optimum proportion of fly ash definitely takes part in the improvement of strength and compressibility ${ }^{3}$. Fly ash disperses large clay-cement clusters formed due to physicochemical interaction into smaller clusters, hence increasing the surface reaction for hydration and pozzolanic reactions and producing larger amount of cementitious products.

As a consequence of the widespread use of biomass fuels for combustion process in Thailand, an agricultural based country, plentiful amounts of biomass ash (BA) are produced and accumulated for further disposal. Certain kinds of BA such as those from rice husk, pine chips, and sugar cane straw contain high amounts of alumina and silica, and when combined with $\mathrm{Ca}(\mathrm{OH})_{2}$ cause the pozzolanic reaction in the presence of water ${ }^{4}$. To improve the economic and environmental impact, some waste $\mathrm{Ca}(\mathrm{OH})_{2}$ rich materials can be used together with waste BA to develop a cementitious material. Calcium carbide residue (CCR) is a by-product of the acetylene production process, which contains mainly $\mathrm{Ca}(\mathrm{OH})_{2}$. During the 1990s, a large amount of CCR in slurry form, which was estimated at $21500 \mathrm{t} /$ year, was left over 
on the detention ponds for sun drying ${ }^{5}$. Its production is described as $\mathrm{CaC}_{2}+2 \mathrm{H}_{2} \mathrm{O} \longrightarrow \mathrm{C}_{2} \mathrm{H}_{2}+\mathrm{Ca}(\mathrm{OH})_{2}$, so $64 \mathrm{~g}$ of calcium carbide $\left(\mathrm{CaC}_{2}\right)$ provides $26 \mathrm{~g}$ of acetylene gas $\left(\mathrm{C}_{2} \mathrm{H}_{2}\right)$ and $74 \mathrm{~g}$ of CCR in terms of $\mathrm{Ca}(\mathrm{OH})_{2}$. Compared to hydrated lime, CCR has similar chemical and mineralogical compositions except for the presence of carbon $(\approx 2 \%)$ in the $\mathrm{CCR}^{1,6}$. The roles of CCR and hydrated lime on the stabilization of soft clayey soil are the same. Rafalko et $\mathrm{al}^{7}$ explained that for the short term reaction, high concentrations of calcium ions initiate the ion exchange with cations on the clay surface. A weak dispersed structure of clay then turned to a strong flocculated one. The increase in the $\mathrm{pH}$ of soil water by $\mathrm{Ca}(\mathrm{OH})_{2}$ causes a gradual dissolution of the silica and alumina from clay. The dissolved silica and alumina then react with calcium ions and produce calcium silicate hydrate and calcium aluminate hydrate by the long term mechanism, pozzolanic reaction.

A mixture of the proper combination of $\mathrm{CCR}$ and $\mathrm{BA}$ (CCR:BA = 60:40) has been found suitable to stabilize the soft Bangkok clay ${ }^{8}$. The pozzolanic reaction took place when CCR reacted with the dissolved silica and alumina from clay and BA. The use of CCR and $\mathrm{BA}$ as a cementing agent refine the microstructure of the stabilized clay, resulting in the improvement of engineering properties (strength, compressibility, permeability, and durability). The microstructure refers to fabric that is the arrangement of the particles, particle group, and pore spaces in the soil as well as cementation. A cluster is a grouping of particles or aggregates into large fabric units and the fabric is composed of groupings of clusters ${ }^{9}$. The microstructure development due to the chemical stabilization has not been well established so far. It is however fundamental to be examined for better understanding and analysing the engineering properties of the CCR and BA stabilized clay.

This paper aims to examine the effects of initial water content, binder content, and curing times on the unconfined compressive strength of the CCR and BA stabilized clay for the short and long term periods. The strength development is then analysed based on the microstructural consideration. Scanning electron microscope (SEM), X-ray fluorescence (XRF), and $\mathrm{X}$-ray diffraction (XRD) were employed to identify the cementitious products from pozzolanic reaction.

\section{MATERIALS AND METHODS}

\section{Materials}

Soft Bangkok clay from Bangkapi District, Bangkok was collected at a depth of approximately $4 \mathrm{~m}$. The
Table 1 Chemical compositions of raw materials used by XRF.

\begin{tabular}{lccr}
\hline & \multicolumn{3}{c}{ Chemical composition $(\%)$} \\
\cline { 2 - 4 } & Bangkok clay & CCR & BA \\
\hline $\mathrm{SiO}_{2}$ & 63.83 & 5.46 & 74.12 \\
$\mathrm{Al}_{2} \mathrm{O}_{3}$ & 21.34 & 2.48 & 0.57 \\
$\mathrm{Fe}_{2} \mathrm{O}_{3}$ & 8.41 & 0.69 & 0.88 \\
$\mathrm{CaO}$ & 0.94 & 80.10 & 5.91 \\
$\mathrm{MgO}$ & 1.54 & 0.75 & 1.54 \\
$\mathrm{SO}_{3}$ & 1.22 & 0.88 & 0.50 \\
$\mathrm{Na}_{2} \mathrm{O}$ & 0.28 & 0.05 & 3.33 \\
$\mathrm{~K}_{2} \mathrm{O}$ & 2.45 & 0.08 & 1.71 \\
$\mathrm{LOI}$ & - & - & 7.45 \\
\hline
\end{tabular}

natural water content was about $80 \%$. The specific gravity was 2.76 . The liquid and plastic limits were $81 \%$ and $35 \%$, respectively. The soil sample was classified as high plasticity clay $(\mathrm{CH})$ according to the Unified Soil Classification System. Soil sample was passed through sieve No. $4(16 \mathrm{~mm})$ before mixing with the CCR and BA to remove the coarser particles. The maximum dry density and optimum water content (OWC) of the clay under standard Proctor energy were $14.4 \mathrm{kN} / \mathrm{m}^{3}$ and $21.5 \%$, respectively.

The CCR, a greyish white coloured solid, was collected from a detention pond of the Sai 5 Acetylene gas factory in Nakhon Pathom province. It was oven dried at $200{ }^{\circ} \mathrm{C}$ for $4 \mathrm{~h}$. BA generated from the combustion process of the National power supply plant in Chachoengsao province was used in this study. The biomass was composed of $42 \%$ rice husk, $24 \%$ bark, $23 \%$ eucalyptus chips, and $6 \%$ board. It was grounded to smaller sizes by a Los Angeles abrasion machine prior to passing through sieve No. $325(45 \mu \mathrm{m})$. The specific gravities of CCR and BA were 2.25 and 1.95 , respectively. The binders were mixed with distilled water at water to solid ratio of $2: 1$ prior to $\mathrm{pH}$ measurement. The $\mathrm{pH}$ of CCR and $\mathrm{BA}$ at $20^{\circ} \mathrm{C}$ was 12.6 and 9.3, respectively, using a Lab 850 set Schott $\mathrm{pH}$ meter. The chemical compositions and major crystalline phases of the raw materials (clay, $\mathrm{CCR}$, and BA) were identified by the XRF and the $\mathrm{XRD}$ analyses.

The chemical compositions of the raw materials are summarized in Table 1. The CCR contained 80\% $\mathrm{CaO}$, almost the same as hydrated lime. The $\mathrm{BA}$ mainly consisted of $\mathrm{SiO}_{2}$ but contained low $\mathrm{CaO}$. The XRD analysis (Fig. 1) indicated that Bangkok clay mainly consisted of quartz and kaolinite. Moreover, the XRD pattern of the BA demonstrated the substantial amorphous phase structure at $2 \theta$ from $3-$ 

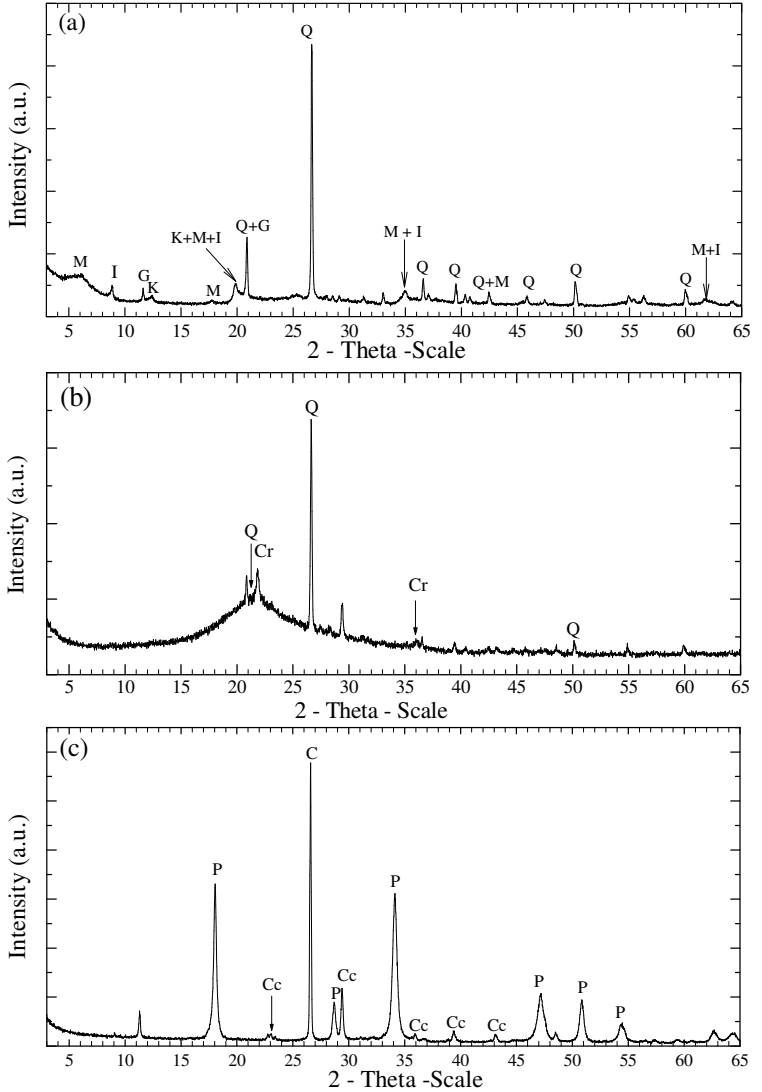

Fig. 1 XRD patterns of raw materials: (a) clay, (b) biomass fly ash (BA), and (c) calcium carbide residue (CCR). (C: carbon, Cc: calcite, Cr: cristobalite, G: gypsum, I: illite, $\mathrm{K}$ : kaolinite, M: montmorillonite, $\mathrm{P}$ : portlandite, Q: quartz).

$20^{\circ}$ and peaks of crystalline quartz and cristobalite. The presence of diffuse reflection at $22^{\circ}<2 \theta<26^{\circ}$ represented the amorphous silica ${ }^{10,11}$. Although the $\mathrm{XRF}$ results show that $\mathrm{CaO}$ content in the $\mathrm{BA}$ was approximately $6 \%$, the main peaks of portlandite $\left(\mathrm{Ca}(\mathrm{OH})_{2}\right)$ were not observed. Therefore, the BA itself does not act as a cementing agent. The detected crystalline substances found in the CCR were portlandite, calcite $\left(\mathrm{CaCO}_{3}\right)$, and carbon. The detection of calcite in the CCR was the consequence from the carbonation of $\mathrm{Ca}(\mathrm{OH})_{2}$ during the deposition in the open air detention pond. The SEM images of the Bangkok clay, the BA, and the CCR are demonstrated in Fig. 2.

\section{Methods}

The test mixtures were prepared to observe the strength and microstructure development in the stabilized clay for different initial soil water content, binder content, proportion of CCR and BA (CCR:BA),
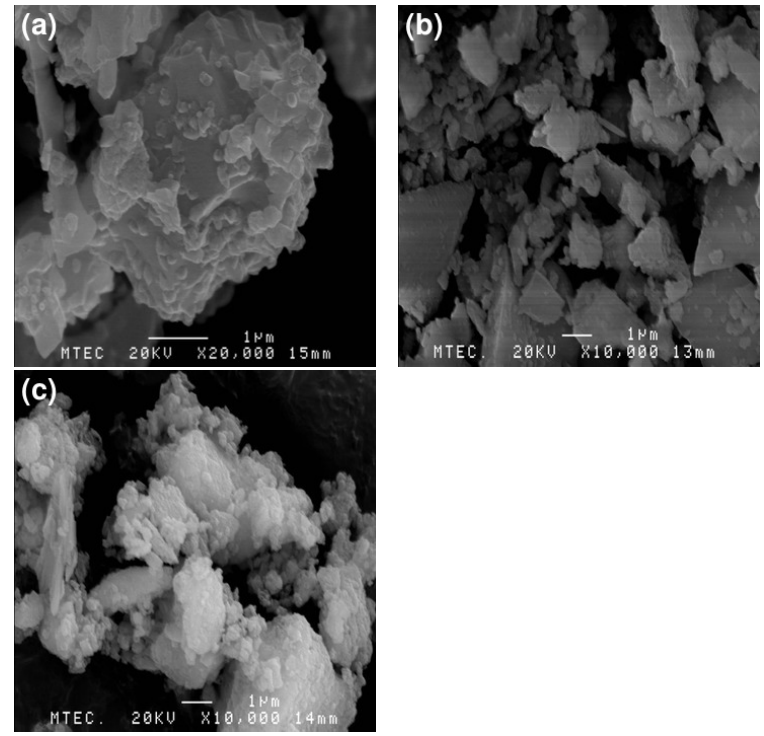

Fig. 2 SEM photos of raw material used: (a) Bangkok clay, (b) BA, and (c) CCR.

and curing time. The water content was adjusted from 0.8-1.4 times of OWC. The Bangkok clay at this water content range was mixed with the blend binder at different content from 5-30\% under five different proportions of $\mathrm{CCR}$ and $\mathrm{BA}$ (CCR:BA = 40:60, 50:50, 60:40, 70:30, and 80:20) and compacted under standard Proctor energy in a cylindrical mould, $50 \mathrm{~mm}$ in diameter and $100 \mathrm{~mm}$ in height. For all samples, soil and binder were mixed thoroughly for $10 \mathrm{~min}$ as recommended by Miura et al ${ }^{12}$ and Horpibulsuk et al ${ }^{13}$. To preserve water content in soil, specimens were cured in plastic sheet under controlled temperature at $20 \pm 1{ }^{\circ} \mathrm{C}$ until desired curing times. The strength tests were performed after 7, 28, 90, and 150 days of curing. The rate of vertical displacement was fixed at $1 \mathrm{~mm} / \mathrm{min}$. Under the same testing conditions, at least eight samples were tested to ensure the test consistency. For all tests, $S D / \bar{x}$ is less than $10 \%$, where $S D$ is standard deviation and $\bar{x}$ is arithmetic mean.

A JEOL JSM 6301F SEM was used to study the changes in microstructure of stabilized soil samples at different mix proportions and curing times. An energy dispersive X-ray spectroscopy (EDS) unit was used to figure out the chemical compositions of interesting crystals. The results from SEM with EDS provide information on pozzolanic products that substantiate the identification of chemical compounds by XRD. The stabilized samples were broken into small fragments at every testing date. The fractured specimens were then dried at $105^{\circ} \mathrm{C}$ for $24 \mathrm{~h}$ to evaporate the residual 

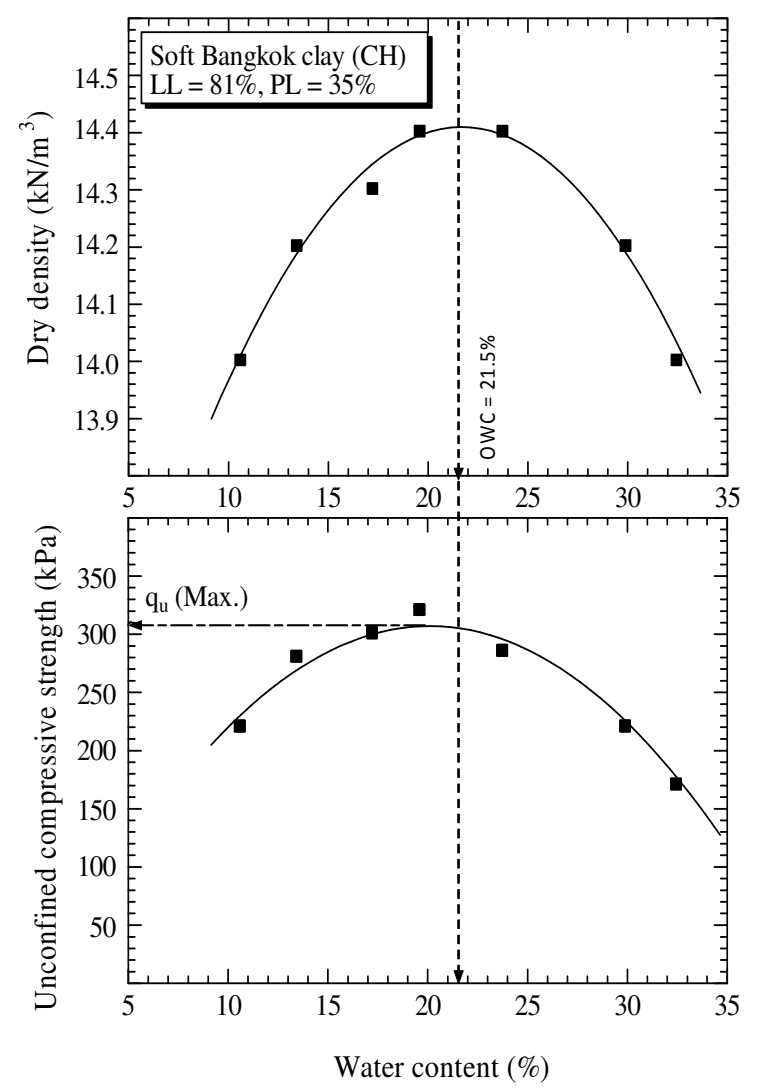

Fig. 3 Compaction and strength curves of Bangkok clay.

moisture and stored in seal containers for tests.

The mineralogical compositions of the stabilized samples at different curing times were examined by XRD analysis. The results show the evidence of pozzolanic reaction. Samples were grounded into powder form before the XRD measurements. The XRD spectra for all samples were recorded and qualitatively analysed by X-Ray Diffractometer, Bruker AXS Model D-8 Discover. The measurement conditions covered an angular range of $3-65^{\circ}$ of $2 \theta$, with step size $0.02^{\circ}$ and a scan time of $0.5 \mathrm{~s}$ per step.

\section{RESULTS AND DISCUSSION}

\section{Strength development}

Standard compaction and unconfined compression test results of the Bangkok clay are shown in Fig. 3. The curve of unconfined compressive strengths at different initial water content demonstrated the similar relationship to the compaction curve. The strengths of unstabilized clay increase with increasing initial water content up to the OWC. The initial water content beyond the OWC cause a reduction in strength. The

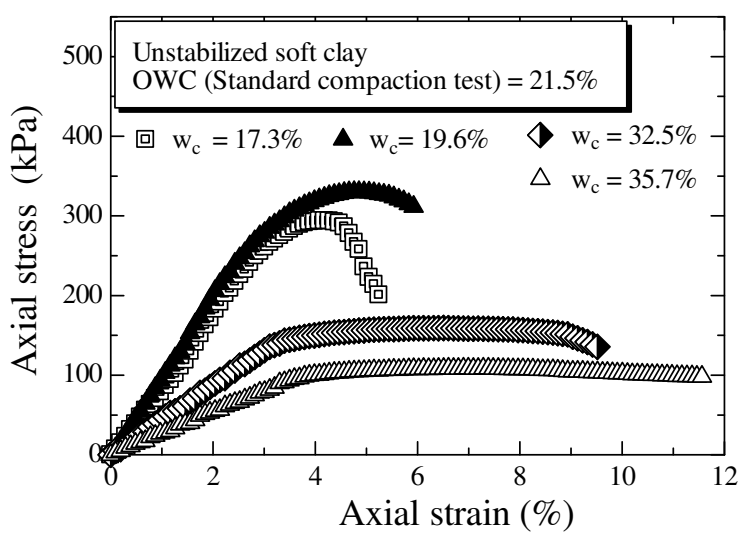

Fig. 4 Axial stress and strain curves of the compacted Bangkok clay.

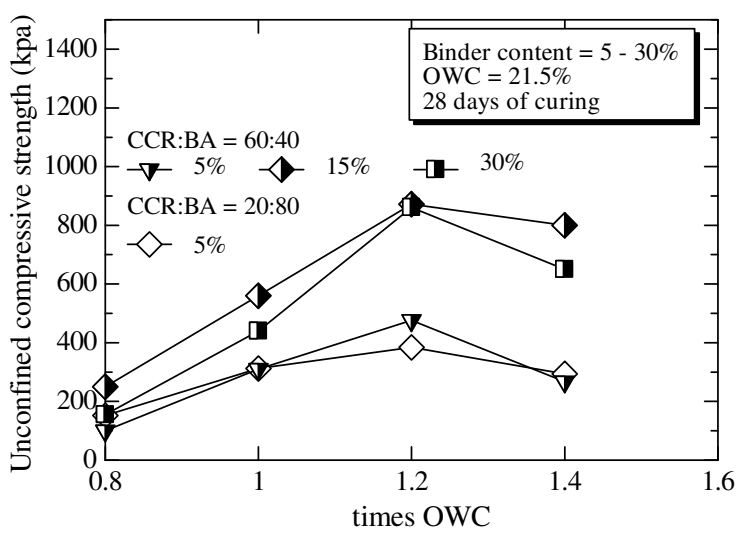

Fig. 5 Strength development of clay stabilized with CCR and BA at different initial water content and binder content for 28 days of curing.

highest strength is at a soil water content slightly lower than the OWC, which is typical for compacted clay $^{14}$. The stress-strain curves of soft Bangkok clay at different initial water content were presented in Fig. 4. The natural clay on the dry side of optimum exhibits a brittle behaviour. The stiffness and strength increase as the water content increases. On the other hand, they decrease as the water content increases for the samples on the wet side of optimum.

The influence of initial water content on unconfined compressive strength of the blended CCR stabilized clay is shown in Fig. 5. Unlike the unstabilized clay, the initial clay water content at 1.2 OWC (25.8\%) provides the highest strength for the stabilized clay. This is because the lower water content is not enough for pozzolanic reaction while the higher water content causes a high water/binder ratio $(W / B)$. The higher 


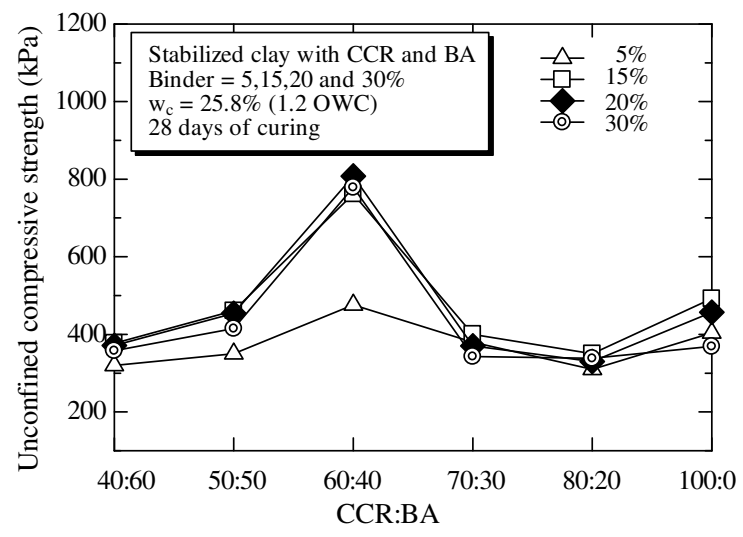

Fig. 6 Strength development of stabilized clay with different CCR:BA ratios.

the $W / B$, the lower the strength is ${ }^{13,15,16}$. This result is the same as that of the cement stabilized clay ${ }^{3,14}$.

Fig. 6 shows the role of the replacement ratio on the strength development at 28 days of curing. The strength of CCR stabilized clay (CCR:BA $=100: 0)$ is presented as a reference. The strength of the CCR stabilized clay slightly increases as the CCR content increases and then decreases when the CCR content is in excess of $15 \%$. For the blended CCR stabilized clay, the CCR:BA ratio of 60:40 provides the highest strength for all binder content tested while the other mix ratios give slightly lower strength than the reference value (CCR:BA ratio of 100:0).

The roles of binder content for different curing times on strength development at the appropriate water content (1.2 OWC) is illustrated in Fig. 7. The bottom panel presents the strength values of the CCR stabilized clay (no BA) at different binder content and curing times (reference values). It is noted that the strength sharply increases with the CCR content and then decreases at about 15\% CCR. The decrease in the strength is caused by the unsoundness due to free lime. This characteristic is also found in concrete containing high free lime content ${ }^{1}$. The drastic increase in the strength of the blended stabilized clay is observed at $5-15 \%$ binders, and the strength gradually decreases when the binder content is in excess of $15 \%$ (see top panel of Fig. 7). For low binder content ( $B=$ $5 \%$ ), the strengths of the stabilized clay with and without CCR are almost the same. In other words, the replacement by the BA insignificantly enhances the strength development. The strengths of blended CCR stabilized clay are greater than those of the CCR stabilized clay when binder content are higher than $5 \%$. The same strength development pattern is found
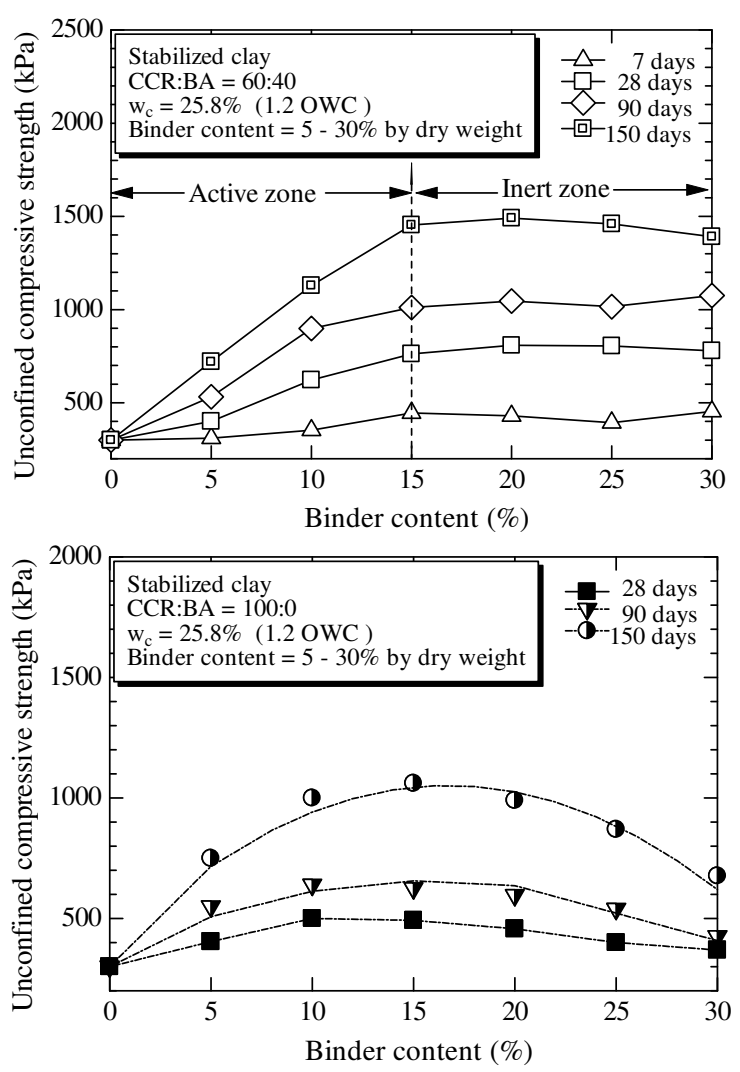

Fig. 7 Strength development of clay stabilized with CCR and BA at different binder content for 7, 28, 90, and 150 days of curing.

for all the curing times tested.

The improvement by the blended CCR can be classified into two zones: active $(B=5-15 \%)$ and inert $(B>15 \%)$. For $B<5 \%$, the natural pozzolanic material in the Bangkok clay is high enough for pozzolanic reaction; the input of the BA is not necessary. This finding is in agreement with the results of the CCR stabilized silty clay by Horpibulsuk et al ${ }^{1}$. The strength remarkably increases with binder content up to an optimal point (active zone) and then the strength insignificantly changes with the input of the binder (inert zone). In the active zone, the $\mathrm{Ca}(\mathrm{OH})_{2}$ content from the CCR are high and the natural pozzolanic material in the clay is not sufficient for the reaction. The input of the $\mathrm{BA}$ increases the $\mathrm{SiO}_{2}$ content and induces the strength development as clearly seen that the strengths of the blended CCR stabilized clay are higher than those of the CCR stabilized clay. But for a larger input of binder $(B>15 \%)$, even though the strength development is insignificant, the input of BA can improve the retardant effect from the 

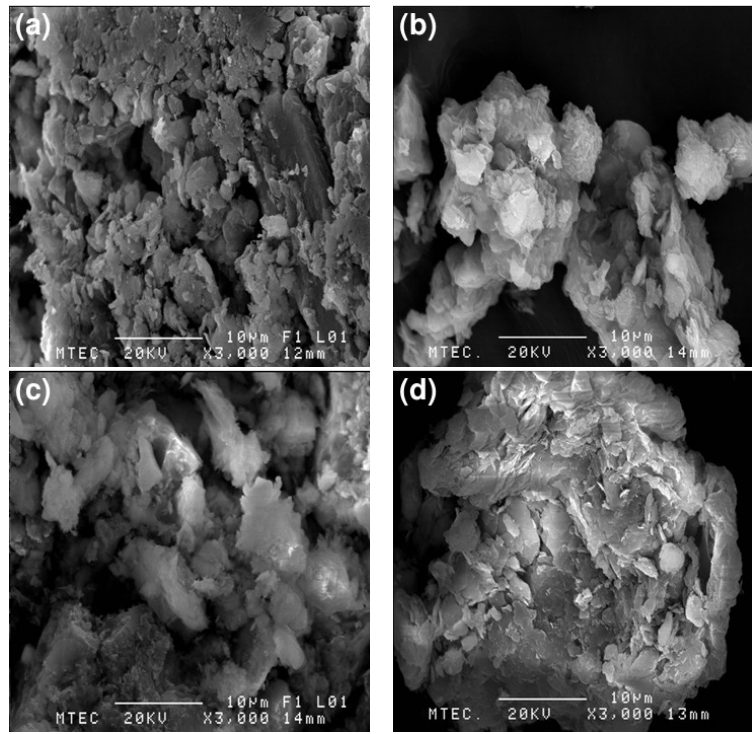

Fig. 8 SEM images of stabilized clay: (a) $10 \%$ binder at 28 days of curing, (b) $10 \%$ binder at 90 days of curing, (c) $20 \%$ binder at 28 days of curing, and (d) $20 \%$ binder at 90 days of curing.

unsoundness caused by the excessive CCR. It should be noted that the optimal binder content is $15 \%$ and it is not economic to improve the soil with higher binder content.

\section{Microstructural analysis}

Fig. 8 shows the surface morphology of the Bangkok clay stabilized with 10 and $20 \%$ binder at 28 and 90 days of curing. At 28 days of curing, the $20 \%$ binder sample (Fig. 8c) developed more aggregates than the $10 \%$ binder sample (Fig. 8a). This implies that the $20 \%$ binder sample renders higher amount of pozzolanic products, bonding among the clay particles. The longer curing time brings about the change in microstructure of both 10 and $20 \%$ binder samples. The morphology of the 90-day samples (Figs. $8 \mathrm{~b}$ and $8 \mathrm{~d}$ ) is denser than that of the 28-day samples. This denser morphology is caused by the filling of the cementitious products from the pozzolanic reaction in the pore space. The denser morphology with curing time is associated with the strength increase.

Fig. 9 shows SEM images with EDS of the stabilized clay with $30 \%$ binder at 28, 90, and 150 days of curing. A very long single rectangular crystal is observed in the stabilized sample that was cured for 28 days (Fig. 9a). The result from the EDS reveals that this crystal is mainly composed of $\mathrm{Si}, \mathrm{Ca}, \mathrm{Al}$, and O. The SEM image of the 90-day specimen (Fig. 9b) illustrates that the stabilized clay particles are coated
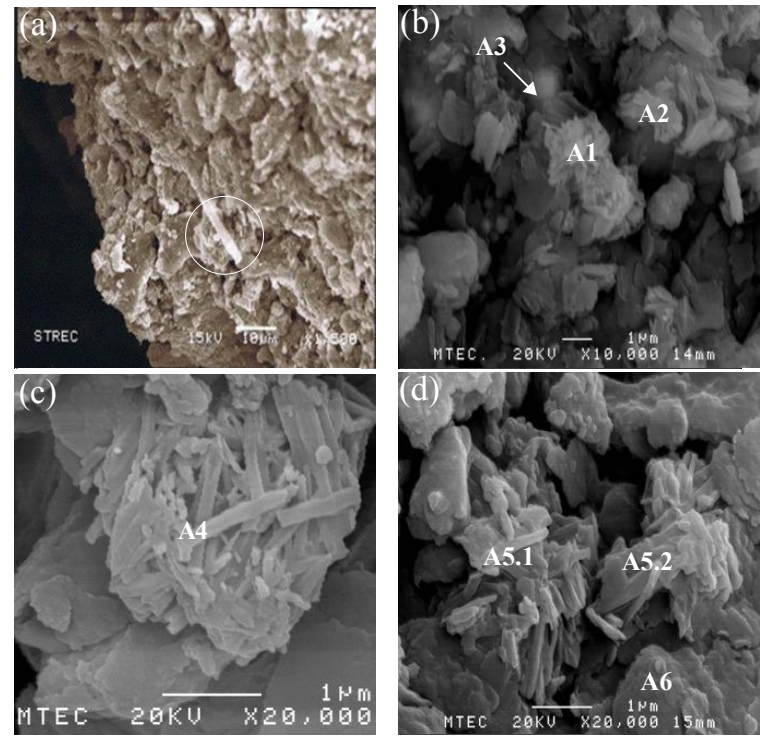

Fig. 9 SEM images of stabilized clay with $30 \%$ binder at different curing times: (a) 28 days, (b) 90 days, (c) and (d) 150 days.

with massive fibrous calcium aluminate silicate hydrate $(\mathrm{C}-\mathrm{A}-\mathrm{S}-\mathrm{H})$ crystals in the areas of A1 and A2. Further, the small rectangular C-A-S-H crystals in area $\mathrm{A} 3$ are attached on the edge. When the curing time is prolonged to 150 days, the large aggregated crystals (area A4) are noticed with a background of cluster plates of clay (Fig. 9c). This close-up image also shows the stacks of dipyramid-like crystals that are suspected to be gismondine ${ }^{17}$. Fig. 9d exhibits the filling of C-A-S-H products (areas A5.1 and A5.2) in the spaces among the low $\mathrm{Ca}$ content crystals (area A6), supposed to be clay particles. The occurrence of these C-A-S-H compounds is the evidence showing the pozzolanic reaction in the blend of hydrolysed $\mathrm{CCR}$ and natural pozzolan. The high $\mathrm{pH}$ solution of $\mathrm{Ca}(\mathrm{OH})_{2}(\mathrm{pH} \geqslant 12.5)$ initiated the rapid dissolution of amorphous $\mathrm{Si}$ at room temperature ${ }^{18,19}$. The similar effect on dissolution of $\mathrm{Al}_{2} \mathrm{O}_{3}$ was due to its lower bonding energy compared to $\mathrm{Si}-\mathrm{O}$ bond ${ }^{19}$. The dissolved $\mathrm{Al}$ and $\mathrm{Si}$ then reacted with $\mathrm{Ca}^{2+}$ ions and consequently formed various types of C-A-S-H in Bangkok clay.

The XRD results of $30 \%$ binder samples (Fig. 10) show quite similar patterns for 28, 90, and 150 days of curing. The XRD patterns clearly indicate the presence of two pozzolanic products: ettringite $\left(\mathrm{Ca}_{2} \mathrm{Al}_{2}\left(\mathrm{SO}_{4}\right)_{3} \cdot 32 \mathrm{H}_{2} \mathrm{O}\right)$ and gismondine $\left(\mathrm{CaAl}_{2} \mathrm{Si}_{2} \mathrm{O}_{8} \cdot 4 \mathrm{H}_{2} \mathrm{O}\right)$ crystals. At high $\mathrm{pH}$ conditions, $\mathrm{Ca}(\mathrm{OH})_{2}$ solubilizes alumina which then reacts with 


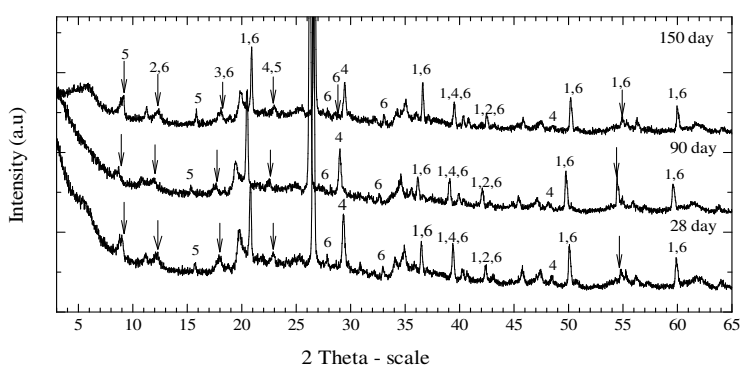

Fig. 10 XRD spectra of stabilized clay at 28, 90, and 150 days of curing (1: quartz, 2: kaolinite, 3: portlandite, 4: calcite, 5: ettringite, 6: gismondine).

either dissolved $\mathrm{CaSO}_{4}$ or $\mathrm{CaSO}_{3}$ producing ettringite. This is the so-called sulpho-pozzolanic reaction. This reaction leads to the dissociation of glass structure and eventually a denser structure and higher strength ${ }^{20}$. The results from XRF and XRD of Bangkok clay indicate that the sulphur content in the clay is the crystalline phase of gypsum $\left(\mathrm{CaSO}_{4} \cdot 2 \mathrm{H}_{2} \mathrm{O}\right)$. This gypsum accelerates the interaction between CCR and $\mathrm{BA}$, forming the hydration products such as ettringite and amorphous calcium silicate hydrate ${ }^{20-22}$.

The presence of bipyramid C-A-S-H crystals from SEM images (Fig. 9c) confirmed the identification of gismondine by XRD examination. On the evidence of these results, the soil improvement by CCR and BA with the most suitable proportion (60:40) can raise the $\mathrm{pH}$ and accelerate the pozzolanic reaction, which forms C-A-S-H compounds. Although the main peaks of gismondine are masked by quartz, a comparative examination of the intensity of reflections at different curing times shows that a peak of gismondine at $28.494^{\circ} 2 \theta$ at 150 days is much more intense compared to those of 28 and 90 days as the result from the progress of pozzolanic reaction. Based on this observation, gismondine is the main cementitious product that contributes to the long term strength development in clay. Antiohos et $\mathrm{al}^{23}$ examined the microstructure of activated FA with quick lime by SEM, XRD, and mercury intrusion porosity. They explained that the faster liberation of amorphous silica from the glass phase of FA in the presence of lime causes the formation of gismondine (and some gehlenite). Gismondine is responsible for filling the pores and for the reduction of porosity in concrete.

For clay stabilized with CCR and BA, the decrease in the intensity of the reflection of either quartz or kaolinite by XRD is not depicted as the progress of curing. Succinctly, the amounts of these Si compounds hardly change with curing time. It provided the conclusion that amorphous silica from the glass of BA could be more reactive in dissolution in CCR than the crystalline phase of quartz and kaolin in clay.

\section{CONCLUSIONS}

The stabilization of soft Bangkok clay by the mixture of CCR and BA increases the unconfined compressive strength and improves the microstructure due to the pozzolanic reaction. The strength development depends on certain key factors: CCR:BA ratio, soil water content, binder content, and curing times. This study leads to the following conclusions: (1) The initial soil water content of $1.2 \mathrm{OWC}$ is the most appropriate mixing state for the initiation of physical and chemical processes. The CCR:BA ratio of 60:40 is the most suitable proportion in achieving the maximum strength of stabilized clay. (2) The strength development in the stabilized clay is classified into two zones: active $(B=5-15 \%)$ and inert $(B>15 \%)$. The $15 \%$ binder is the appropriate quantity or the practical amount for the stabilization of Bangkok clay. In the active zone, the input $\mathrm{BA}$ increases the $\mathrm{SiO}_{2}$ content and induces the strength development. The high CCR content in the inert zone causes unsoundness due to free lime, hence insignificant strength development. (3) Ettringite and gismondine are the main products found in stabilized clay with the blend of CCR and $\mathrm{BA}$ at room temperature. Gismondine is responsible for the long term strength gain. The hydrolysis of CCR with water causes the very high $\mathrm{pH}$ solution and then rapid dissolution of amorphous $\mathrm{Si}$ and $\mathrm{Al}$ as well. Amorphous Si from BA is the reactant in pozzolanic reaction because of its high reactivity in base solution comparing the other $\mathrm{Si}$ oxides in clay. (4) The denser clay structure is observed for higher binder content due to the growth of the cementitious products from pozzolanic reaction. Over the curing times, the silica from the BA and clay is gradually dissolved and reacted with the CCR to form supplementary cementitious products (C-A-S-H), leading to the subsequent filling of pore space and the higher strength.

Acknowledgements: The authors acknowledge Mahanakorn University for supporting this study. A special thank you to Mr. Manop Tirarattanasompot of the Scientific and Technological Research Equipment Centre, Chulalongkorn University for his insightful remarks during XRD examination. Grateful acknowledgement is also given to Miss Acharaporn Srion of the National Metal and Materials Technology Centre (MTECH) for her skilful assistance with SEM examination. 


\section{REFERENCES}

1. Horpibulsuk S, Phetchuay C, Chinkulkijniwat A (2011) Soil stabilization by calcium carbide residue and fly ash. J Mater Civ Eng 24, 184-93.

2. Saylak D, Mishra SK, Mejeoumov GG, Shon C (2008) Fly ash-calcium chloride stabilization in road construction. Transport Res Rec 2053, 23-9.

3. Horpibulsuk S, Rachan R, Raksachon Y (2009) Role of fly ash on strength and microstructure development in blended cement stabilized silty clay. Soils Found $\mathbf{4 9}$, $85-98$.

4. Ahmaruzzaman M (2009) A review on the utilization of fly ash. Progr Energ Combust Sci 36, 327-63.

5. Tanalapsakul A (1998) Document from M Thai Industrial Company Limited. May. M Thai Industrial Co. Ltd, Samutsakorn, Thailand.

6. Cardoso FA, Fernandes HC, Pileggi RG, Cincotto MA, John VM (2009) Carbide lime and industrial hydrated lime characterization. Powder Tech 195, 143-9.

7. Rafalko SD, Brandon TL, Filz GM, Mitchell JK (2007) Rapid chemical stabilization of soft clay soils. Transport Res Rec 2026, 39-46.

8. Vichan S, Rachan R (2010) Potential use of calcium carbide residue and biomass fly ash as cement substitution for soil stabilization. In: Proceedings of the 7th International Symposium on Lowland Technology, Saga Japan, pp 90-7.

9. Mitchell JK (1993) Fundamentals of Soil Behavior. New York: John Wiley \& Sons, Inc.

10. Anderson D, Roy A, Seals RK, Carledge FK, Akhter H, Jones SC (2000) A preliminary assessment of the use of an amorphous silica residual as a supplementary cementing material. Cement Concr Res 30, 437-45.

11. Davarz M, Gunduz L (2005) Engineering prperties of amorphous silica as a new natural pozzolan for use in concrete. Cement Concr Res 35, 1251-61.

12. Miura N, Horpibulsuk S, Nagaraj TS (2001) Engineering behavior of cement stabilized clay at high water content. Soils Found 41, 33-45.

13. Horpibulsuk S, Miura N, Nagaraj TS (2003) Assessment of strength development in cement admixed high water content clays with Abraham's law as a basis. Geotechnique 53, 439-44.

14. Horpibulsuk S, Rachan $\mathrm{R}$, Chinkulkinijniwat A, Rakasachon Y (2010) Analysis of strength development in cement-stabilized silty clay from microstructural considerations. Construct Build Mater 24, 2011-21.

15. Horpibulsuk S, Katkan W, Sirilerdwattana W, Rachan R (2006) Strength development in cement stabilized low plasticity and coarse grained soils: Laboratory and field study. Soils Found 46, 351-66.

16. Horpibulsuk S, Rachan R, Suddeepong A (2011) Assessment of strength development in blended cement admixed Bangkok clay. Construct Build Mater 25, $1521-31$
17. Anthony JW, Bideaux RA, Bladh KW, Nichols MC (2001) Handbook of Mineralogy, Mineralogical Society of America, Chantilly, VA 20151-1110, USA.

18. Tang M, Han S (1981) Effect of $\mathrm{Ca}(\mathrm{OH})_{2}$ on the alkalisilica reaction. J Chin Silica Soc 9, 160-6.

19. Shi C, Day RL (2000) Pozzolanic reaction in the presence of chemical activators. Part II: Reaction products and mechanism. Cement Concr Res 30, 607-13.

20. Aimin X, Sarkar SL (1991) Microstructural study of gypsum activated fly ash hydration in cement paste. Cement Concr Res 21, 1137-47.

21. Ma W, Liu C, Brown PW, Kormaeneni S (1995) Pore structures of fly ashes activated by $\mathrm{Ca}(\mathrm{OH})_{2}$ and $\mathrm{CaSO}_{4} \cdot 2 \mathrm{H}_{2} \mathrm{O}$. Cement Concr Res 25, 417-25.

22. Ma W, Brown PW (1997) Hydrothermal reactions of fly ash with $\mathrm{Ca}(\mathrm{OH})_{2}$ and $\mathrm{CaSO}_{4} \cdot 2 \mathrm{H}_{2} \mathrm{O}$. Cement Concr Res 27, 1237-48.

23. Antiohos S, Papageorgiou A, Tsimas S (2006) Activation of fly ash cementitiuos systems in the presence of quicklime. Part II: Nature of hydration products, porosity and microstructure development. Cement Concr Res 36, 2123-31. 